\title{
The effectiveness of a rotavirus vaccine in preventing hospitalizations and deaths presumably due to acute infectious diarrhea in Brazilian children: a quasi-experimental study
}

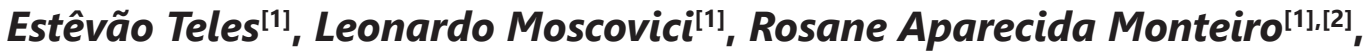 \\ Domingos Alves ${ }^{[1],[2]}$, Milton Roberto Laprega ${ }^{[1,[2]}$ \\ and Fernando Bellissimo-Rodrigues ${ }^{[1]}$
}

[1]. Departamento de Medicina Social, Faculdade de Medicina de Ribeirão Preto, Universidade de São Paulo, Ribeirão Preto, São Paulo,Brasil. [2]. Observatório Regional de Atenção Hospitalar, Faculdade de Medicina de Ribeirão Preto, Universidade de São Paulo, Ribeirão Preto, São Paulo, Brasil.

\begin{abstract}
Introduction: Rotavirus is the main etiologic agent of acute infectious diarrhea in children worldwide. Considering that a rotavirus vaccine (G1P8, strain RIX4414) was added to the Brazilian vaccination schedule in 2006, we aimed to study its effectiveness and safety regarding intestinal intussusception. Methods: A quasi-experimental trial was performed in which the primary outcome was the number of hospitalizations that were presumably due to acute infectious diarrhea per 100,000 children at risk (0-4 years old). The secondary outcomes included mortality due to acute infectious diarrhea and the intestinal intussusception rates in children in the same age range. We analyzed three scenarios: Health Division XIII of the State of São Paulo (DRS XIII) from 2002 to 2008, the State of São Paulo, and Brazil from 2002 to 2012. Results: The averages of the hospitalization rates for 100,000 children in the pre- and post-vaccination periods were 1,413 and 959, respectively, for DRS XIII $(R R=0.67), 312$ and 249, respectively, for the State of São Paulo $(R R=0.79)$, and 718 and 576, respectively, for Brazil $(R R=0.8)$. The mortality rate per 100,000 children in the pre- and post-vaccination periods was 2.0 and 1.3 , respectively, for DRS XIII $(R R=0.66), 5.5$ and 2.5, respectively, for the State of São Paulo $(R R=0.47)$, and 15.0 and 8.0, respectively, for Brazil $(R R=0.53)$. The average annual rates of intussusception for 100,000 children in DRS XIII were 28.0 and $22.0(\mathrm{RR}=0.77)$ in the pre- and postvaccination periods, respectively. Conclusions: A monovalent rotavirus vaccine was demonstrated to be effective in preventing the hospitalizations and deaths of children that were presumably due to acute infectious diarrhea, without increasing the risk of intestinal intussusception.
\end{abstract}

Keywords: Rotavirus. Vaccine. Effectiveness. Infectious acute diarrhea. Intussusception. Mortality.

\section{INTRODUCTION}

Diarrhea is among the most common infections in children between the ages of 0 and 5 years old. The etiology of most cases of diarrhea is infection by rotavirus. Rotavirus transmissions occur by the fecal-oral route, and rotavirus is highly infectious ${ }^{(1)(2)}$. Diarrhea, fever and vomiting are the main symptoms. Oral/intravenous rehydration is the treatment of choice $^{(2)(3)}$. In temperate countries, epidemics occur mainly in the winter, whereas in tropical countries, they occur throughout the year.

Corresponding author: Dr. Fernando Bellissimo-Rodrigues. Dept ${ }^{\circ}$ de Medicina Social/HC/FMRP/USP. Campus Universitário s/n, $2^{\circ}$ andar, Monte Alegre, 14048-900 Ribeirão Preto, São Paulo, Brasil.

Phone: 5516 3602-2714; Fax: 5516 3602-1562

e-mail: fbellissimo@fmrp.usp.br

Received 16 December 2014

Accepted 10 February 2015
Particularly in the central, southern and southeastern regions of Brazil, epidemics occur during the dry season (May through September) ${ }^{(4)(5)(6)(7)}$.

The World Health Organization (WHO) estimated that, in 2008 , approximately 453,000 children died because of rotaviruses around the world ${ }^{(8)}$. Other authors have estimated that 114 million episodes of gastroenteritis, 24 million appointments, 2.4 million hospitalizations and 611,000 deaths occur annually in children younger than 5 years old around the world ${ }^{(9)}$. In the U.S., it is estimated that, in 2006, rotavirus caused 55,000 to 70,000 hospitalizations among children younger than 5 years old ${ }^{(10)}$.

In Brazil, data from the Ministry of Health showed a total spending of $R \$ 173,245,567.85$ between 1995 and 2004 due to diarrheic diseases in children aged 0-5 years of age. From 1996 to 2003, 33,786 children younger than 5 years old died from diarrhea ${ }^{(11)}$.

Studies published before 2000 found that an average of $12-42 \%$ of the hospitalizations and outpatient appointments 
due to diarrheic disease were caused by rotavirus ${ }^{(4)(5)(6)(7)(12)}$. In the northern region of Brazil, between 1982 and 1986, each child had 0.25 diarrheic episodes per year due to rotavirus ${ }^{(13)}$. In 2003, Departamento de Informática do Sistema Único de Saúde (DATASUS) registered a total of 269,195 hospitalizations in children younger than 5 years old due to diarrheic disease. Considering only the children younger than 5 years old, an average of $34 \%$ of these episodes were due to rotavirus; therefore, it could be estimated that 91,526 hospitalizations due to rotavirus occurred in that age range ${ }^{(14)}$. The cost of each hospitalization due to rotavirus was estimated at US\$1,106.13. Similarly, also in Brazil, Sartori et al. ${ }^{(15)}$ calculated a base number of 92,453 hospitalizations and 850 deaths per year due to rotavirus disease $\mathrm{e}^{(15)}$. The cost of this burden was estimated by Constenla et al. ${ }^{(16)}$ at US $\$ 19.3$ million in $2003^{(16)}$.

The first rotavirus vaccine was licensed in 1998; however, it was suspended the following year due to an increase in the number of cases of intestinal intussusception ${ }^{(17)}$. In 2000, a monovalent vaccine - RV1 - containing a live attenuated virus was shown to be effective and safe. Subsequently, it was incorporated into the Brazilian immunization schedule ${ }^{(18)(19)}$. The WHO recommended, in 2007, the inclusion of the rotavirus vaccination in regions where such action would have a major public health impact. Studies in Latin America and Finland have shown high effectiveness in preventing severe gastroenteritis ${ }^{(20)}$.

In 2006, RV1 was adopted in Brazil. Lanzieri et al. ${ }^{(21)}$ showed a $30-39 \%$ reduction in deaths and a $26-48 \%$ reduction in hospitalizations from all causes of diarrhea after the introduction of $\mathrm{RV}^{(21)(22)}$. Carmo et al. ${ }^{(23)}$ had similar results, with a $22-28 \%$ reduction in deaths and a $21-25 \%$ reduction in hospitalizations ${ }^{(23)}$. Sáfadi et al. ${ }^{(24)}$, in a study that specifically evaluated the reduction in hospitalizations due to rotavirus, obtained a $73-82 \%$ reduction after the vaccine was introduced ${ }^{24}$. Another study found a greater reduction in the number of hospitalizations caused by gastroenteritis in children up to 1 year old (35.6\%), compared with children 1-4 years old (reduction of 12.3\%), after children started being vaccinated. The mortality reduction followed the same pattern, decreasing by $54.5 \%$ in children up to 1 year old and by $32.9 \%$ in children $1-4$ years old ${ }^{(25)}$.

Although the first licensed vaccine in the U.S. was linked to increased cases of intestinal intussusception ${ }^{(17)}$, the RV1 vaccine proved to be safe. A randomized, double-blind study evaluated the safety of the vaccine. After following 63,225 children who were divided into 2 groups (one of the groups received placebo), no difference was observed between the rates of intussusception in the two groups ${ }^{(20)}$.

\section{Objectives}

Our main objective was to evaluate the impact of the introduction of the rotavirus vaccine into the Brazilian infant vaccination schedule on the hospitalization rates for presumably acute infectious diarrhea in children aged 0-4 years old in Ribeirão Preto (SP), in the State of São Paulo and throughout Brazil.

The secondary objective of the study was to evaluate the safety of this vaccine, regarding a possible association with intestinal intussusception.

\section{METHODS}

This study was based on a quasi-experimental method, conducting statistical analysis of data contained in the Regional Observatory of Hospital Attention portal [Observatório Regional de Atenção Hospitalar (ORAH)] and Datasus. This study was an effectiveness study of a public health measure (in this case, the introduction of a rotavirus vaccine into the Brazilian vaccination schedule). Similar analyses have been performed in Brazil; however, these analyses used only Datasus, the database of the Brazilian Health System [Sistema Único de Saúde (SUS) ${ }^{(21)(23)}$. Studies using a similar methodology have been performed in the U.S.; however, these studies used the rotavirus pentavalent vaccine ${ }^{(26)(27)}$. Quasi-experimental studies are widely undertaken for the analysis of infectious diseases, particularly when an intervention is administered in a population, such as the introduction of an antibiotic or a vaccine ${ }^{(28)}$.

The study population was children between 0 and 4 years old. This age group was used because it is not possible to specify the range of 0-5 years old in the database, which would have been more appropriate. The analysis was performed in 3 scenarios: the Regional Health Department XIII (Departamento Regional de Saúde XIII - DRS XIII (scenario I), the State of São Paulo (scenario II) and Brazil as a whole (scenario III). The analysis period varied for each scenario: for DRS XIII, it was 2002-2008, due to a lack of data from 2009; for the State of São Paulo and for Brazil as a whole, the period was 2002-2012. The outcomes assessed in each of these scenarios were the number of admissions and mortality from viral and other specified intestinal infections (ICD-10 A08) and other gastroenteritis and colitis of infectious and unspecified origin (ICD-10 A09). To avoid errors, the results were expressed in coefficients per 100,000 inhabitants due to variations in the study population over time. The demographic data were obtained from the census and projections from the Brazilian Institute of Geography and Statistics [Instituto Brasileiro de Geografia e Estatística (IBGE)]. Furthermore, the vaccination coverage was also observed for the 5 geographic regions of Brazil, and it was correlated with the reduction in hospitalizations for the International Statistical Classification of Diseases and Related Health Problems 10th Revision (ICD) codes specified above. The safety of the vaccine was studied by analyzing the occurrence of intussusception (which falls under ICD-10 code K56) before and after the beginning of vaccination.

\section{Databases}

The ORAH portal (used for scenario I) is an initiative of the Center for the Hospital Data Processing, Department of Social Medicine, Faculty of Medicine of Ribeirão Preto, University of São Paulo, and the Health Department of the State of São Paulo. It is centered in Ribeirão Preto and contains data from all of the hospitalizations of all of the public, philanthropic and private hospitals of the Regional Department of Health XIII, involving 26 counties in the northeastern region of São Paulo. Datasus is the database of the entire national public health system, and it contains epidemiological, demographic and socioeconomic information, among other information. Only establishments 
in SUS (used for scenarios II and III) were included. In this database, there is no distinction between ICD-10 codes A08 and A09; therefore, the analysis was performed only on the basis of hospitalizations for other gastroenteritis and colitis of infectious and unspecified origin (ICD A09).

\section{Method of analysis}

In the present study, we used a variant of the quasiexperimental method to avoid possible confounding variables, such as climate variations and increases in sanitation coverage. A second non-equivalent variable was used; however, this variable suffered from the influence of possible confounding variables in the same manner as the study variable. Thus, we avoided possible bias and provided greater reliability to the study. The non-equivalent variable that was used as a correction factor in scenario I consisted of the joint admission data for other enteritis such as Salmonellosis, shigellosis, other bacterial intestinal infections and other bacterial foodborne intoxications, not elsewhere classified (ICD-10 A02, A03, A04 and A05, respectively). For scenarios II and III, we selected all amoebiasis and shigellosis cases as non-equivalent variables. This variable is expressed per million habitants, due to the low prevalence of these diseases in the population. For scenarios II and III, the sum of all of the cases of amoebiasis and shigellosis was used. The data analysis was performed by calculating the relative risks for each of the outcomes in each scenario, both before and after the onset of vaccination, in addition to diagramming the control of the hospitalizations, which contains primarily the monthly average hospitalizations in the pre-intervention period and, as its limits, the endemic channel increased and decreased by 2 standard deviations. Subsequently, a comparison was undertaken between the post-intervention data and the endemic channel.

For intestinal intussusception, we also used the rate of hospitalizations per 100,000 children aged 0-4 years old and the calculation of relative risk. The data were extracted from the ORAH Web site. We searched all of the cases diagnosed as paralytic ileus and intestinal obstruction without hernia (ICD-10 $\mathrm{K} 56)$. The ORAH database does not include the specific ICD-10 for intussusception.

\section{RESULTS}

The graphics in Figure 1 show a significant reduction in hospitalizations due to viral and unspecified gastroenteritis after the introduction of vaccination in 2006. The difference was most marked in DRS XIII, where there was a clear seasonality before 2007. After 2007, the peaks that were previously found from July to October disappeared. In the other remaining scenarios, there were also reductions. In all of the cases, when comparing the rotavirus curve with the control curve, there was a reduction in the first curve, but the second curve maintained the same pattern.

Figure 2 displays the graphics of the endemic channels for each scenario. The post-vaccination (period) curve crosses the lower limit of the endemic channel in all of the curves. In Brazil, the post-vaccination curve is less than the lower limit of the endemic channel from March to December.
The hospitalization percentage reduction was greater in DRS XIII, with a decrease of $33 \%$, compared with $21 \%$ and $20 \%$ for the State of São Paulo and Brazil, respectively (Table 1). In addition, the mortality reduction was similar in São Paulo (53\%) and Brazil (47\%) and was smaller in DRS XIII (34\%). The hospitalizations caused by intussusception were similar in the pre- and post-vaccine periods (pre-vaccine: 28 admissions/100,000 people; post-vaccine: 22 admissions $/ 100,000$ people), with a relative risk of 0.77 .

In 2007, the immunization coverage in the southeast region of Brazil was $86.1 \%$, the largest in Brazil (Table 2). This region had a percentage decrease of $33.7 \%$ in all gastroenteritis admissions, which was also the most important decrease among all of the geographic regions of Brazil. The northern region, with coverage of $62.2 \%$ (the lowest in the country), was also where the reduction was least, with only $1.8 \%$.

\section{DISCUSSION}

The results suggested that the rotavirus vaccine has been effective in protection against rotavirus disease. Both of the assessed outcomes (hospitalizations and mortality) were significantly reduced after the onset of vaccination. In addition, vaccination has been demonstrated to be cost effective by other authors: in 2003, for example, approximately US\$19.3 million were saved in Brazil(16). In the present study, it was estimated that 1,320 deaths were prevented annually in Brazil due to the rotavirus vaccine, accounting for the average mortality before and after the start of vaccination.

We analyzed the hospitalizations for the ICD-10 codes containing rotavirus and other diarrheal diseases and noticed a sharp decrease in hospitalizations from these pathologies, markedly after 2006, when vaccination started; however, the control group showed a slight downward trend without the important decrease observed since 2006. There is a caveat for 2010-2011, during which there was a sharp increase in hospitalizations in the group of diseases that includes rotaviruses. This increase occurred because of outbreaks of diarrheal illness caused by norovirus, mainly in the cities on the coast of the State of São Paulo ${ }^{(29)}$.

In Brazil, we found a total reduction of $20 \%$ among children $0-4$ years old in hospitalizations caused by gastroenteritis. These data were similar to the findings of other studies that showed reductions varying from 17 to $48 \%{ }^{(21)(22)(23)(25)}$. Similarly, the decrease in the mortality rate due to gastroenteritis was greater than the decrease in hospitalization rates $(47 \%$ and $20 \%$, respectively. This result was also in agreement with the findings in the literature ${ }^{(10)(25)}$. An important reduction in admissions caused by gastroenteritis in children occurred in Europe, even in countries with low immunization coverage, for instance ${ }^{(30)}$.

Another important finding was the decrease in the hospitalization rate observed in DRS XIII (40\%) and São Paulo (30\%) between May and September, which was greater than the average decrease in total hospitalizations (33\% and $21 \%$, respectively). This issue is important because rotavirus had a 


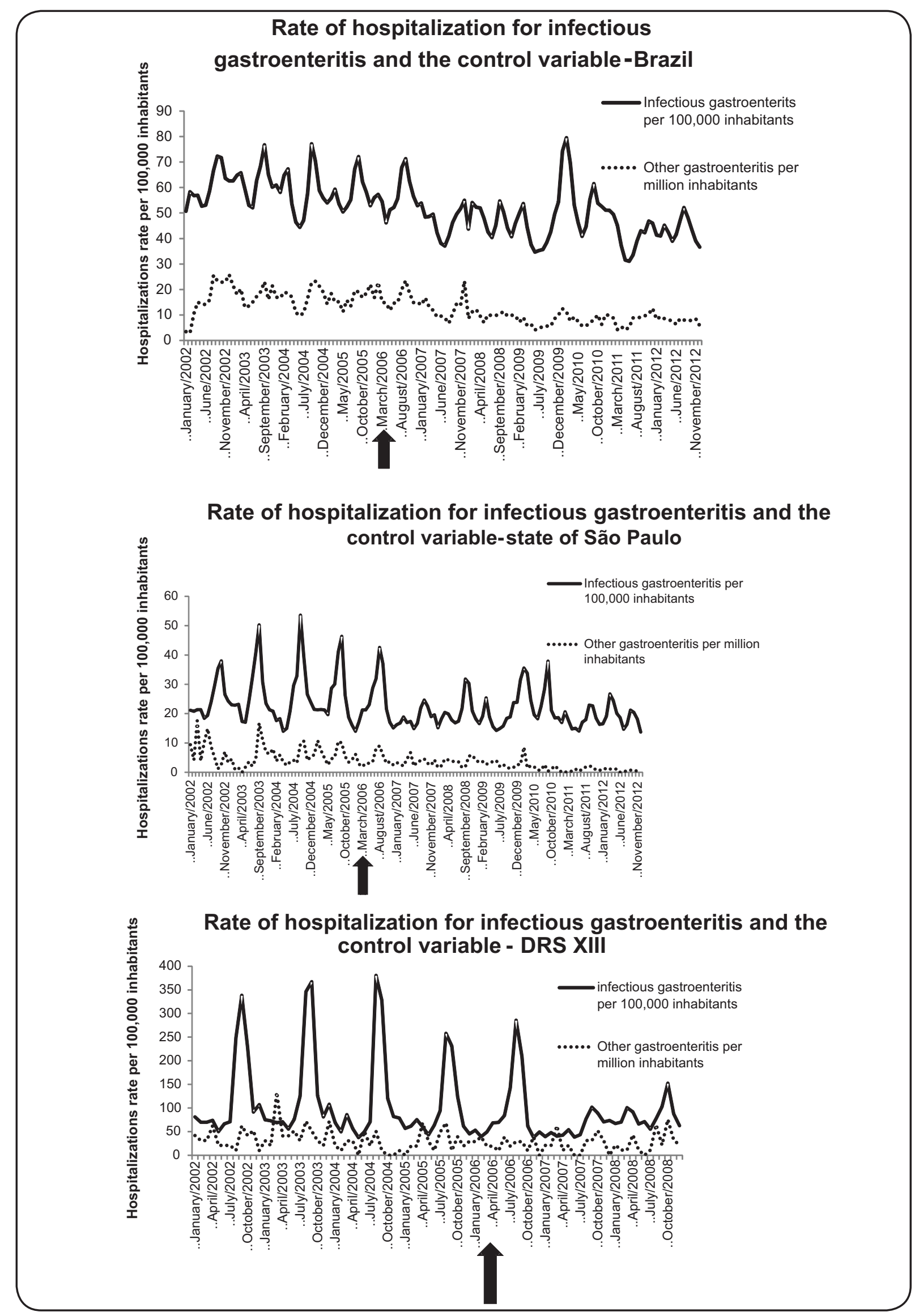

FIGURE 1 - The hospitalizations presumably due to acute infectious diarrhea per 100,000 inhabitants and due to other types of gastroenteritis per million inhabitants, in three different scenarios, before and after the introduction of the universal rotavirus vaccine (arrow). 

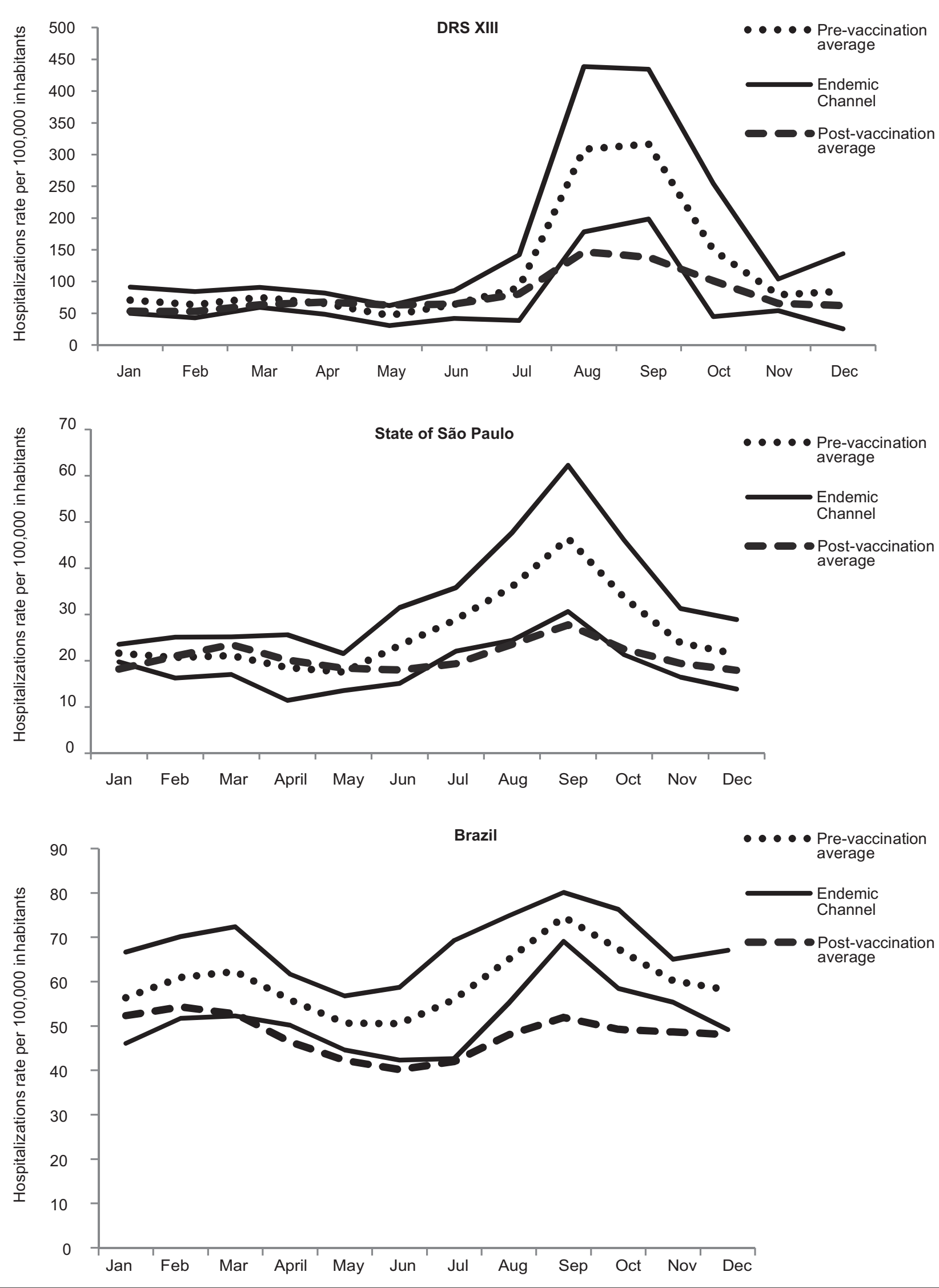

FIGURE 2 - The endemic channels of the hospitalization rates presumably due to acute infectious diarrhea (average \pm 2 standard deviations) in the three studied scenarios, plus the pre- and post-vaccination periods. 
TABLE 1 - The hospitalization and mortality rates presumably due to acute infectious diarrhea per 100,000 children at risk per year in the pre- and post-vaccination periods in three different scenarios.

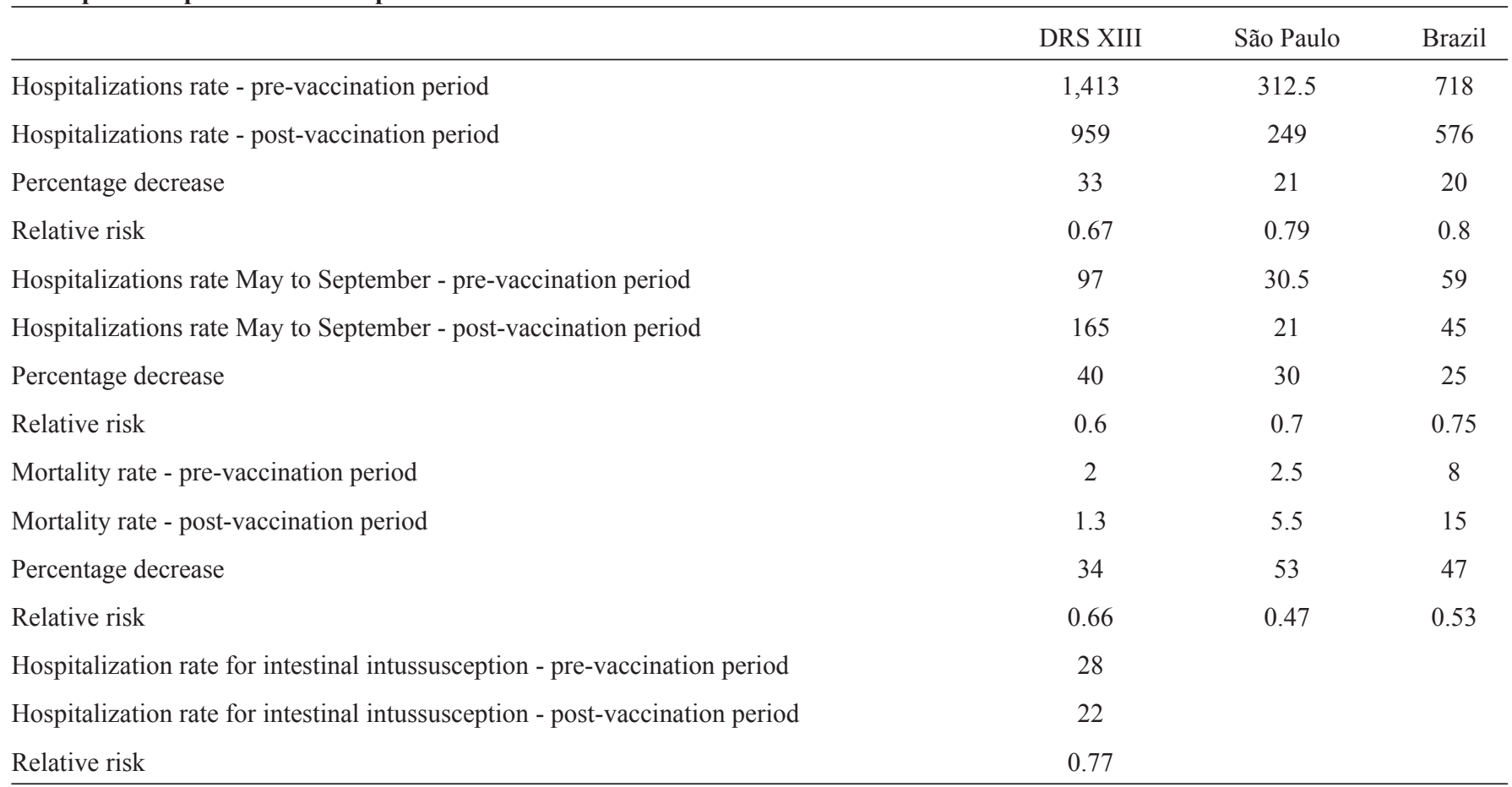

DRS XIII: Regional Department of Health XIII, from the State of São Paulo.

TABLE 2 - The percentage decrease in hospitalizations per 100,000 inhabitants and rotavirus immunization coverage in different geographical regions of Brazil.

Geographical regions

North

Northeast

Southeast

South

Midwest

The percentage decrease in hospitalization rates in 2007 (compared with 2005)
The immunization coverage in 2007 (the percentages of the target populations)

62.27

75.46

86.1

83.39

83.83 higher incidence in these regions during this period. The sharpest decrease in these parameters during that period, compared to other periods of the year, provided additional evidence of the vaccine's effectiveness.

Similarly, when the endemic channel for each scenario was tracked, the average hospitalizations in the post-vaccine period crossed the lower limit in all of the scenarios, and in southeastern Brazil (scenarios I and II), where seasonal rotavirus is the most prevalent, the mean post-vaccination period crossed the lower limit of the endemic channel exactly at the same time that previously had the highest rates of the year. Additionally, in agreement with this result, the immunization coverage data showed a sharper decrease in the hospitalizations in the regions where the coverage was higher, with the exception of the southern region.

Regarding the safety of the vaccine, the data suggested a decrease in cases of intestinal intussusception in the early postvaccination period. This fact speaks in favor of the safety of the vaccine, which is in agreement with the international research ${ }^{(31)}$.

The main limitation of the current study was the absence of an etiological diagnosis of rotavirus. Because diarrheal diseases usually have a self-limited course, the diagnosis of the etiological agent is not normally performed in the Brazilian health system. Therefore, this study had to use the ICD-10 codes for gastroenteritis, not the specific code for rotaviral enteritis (A08.0). This absence of an etiological diagnosis 
requires an effort to seek other methods to avoid the generating of confounding variables, such as the joint analysis of a nonequivalent variable with the variable under study and an analysis of the periods of the highest incidence of the virus, before the introduction of the vaccine, with a subsequent comparison with the post-vaccination period.

In conclusion, a monovalent rotavirus vaccine was demonstrated to be effective in preventing the hospitalizations and deaths of children that were presumably due to acute infectious diarrhea, without increasing the risk of intestinal intussusception.

\section{CONFLICT OF INTEREST}

The authors declare that there is no conflict of interest.

\section{REFERENCES}

1. Sociedade Brasileira de Imunizações. Informe Rotavírus 2006 (Internet) 2006. Cited 2014 February 20. Avaliable at: http://sbim. org.br/sbim_info_rotavirus.pdf

2. Bricks LF. Rotavírus: doenças e vacinas. Pediatria 2005; 27:252-266.

3. Kapikian AZ, Chanock RM. Rotaviruses. In: Fields BN, Knipe DM, Howley PM, Chanock RM, Melnick JL, Monath TP, et al. editors. Virology. $3^{\text {rd }}$ edition. Philadelphia: Lippincott-Raven Publishers. 1996. p. 1657-1708.

4. Gomes TA, Rassi V, MacDonald, KL, Ramos SRTS, Trabulsi LR, Vieira MA, et al. Enteropathogens associated with acute diarrheal diseases in urban infants in São Paulo, Brazil. J Infec Dis 1991; 164:331-337.

5. Teixeira JM, De Figueiredo RB, Dos Santos HM, Ferreira MN, Camara GN. Aspectos epidemiológicos das infecções por rotavírus no Distrito Federal, Brasil. Rev Soc Bras Med Trop 1991; 24:223-230.

6. Cardoso DD, Martins RM, Kitajima EW, Barbosa AJ, Camarota SC, Azevedo MS. Rotavírus e adenovírus em crianças de 0-5 anos hospitalizadas com ou sem gastroenterite em Goiânia-GO, Brasil. Rev Inst Med Tropl de São Paulo 1992; 34:433-439.

7. Stewien KE, Mos EN, Yanaguita RM, Jerez JA, Durigon EL, Hársi CM, et al. Tanaka H, Moraes RM, Silva LA, Santos MA, Candeias JMG, Tanaka K, Peret TCT, Baldacci ER, Clílio AE. Viral, bacterial and parasitic pathogens associated with severe diarrhoea in the city of São Paulo, Brazil. J Diarrhoeal Dis Res 1993; 11:148-152.

8. World Health Organization. Estimated rotavirus deaths for children under 5 years of age: 2008, 453,000 (Internet). World Health Organization. Updated 2014 March 3; Avaliable at: http://www.who. int/immunization/monitoring surveillance/burden

9. Parashar UD, Gibson CJ, Bresee JS, Glass RI. Rotavirus and severe childhood diarrhea. Emerg Infect Dis 2006; 12:304-306.

10. Yen C, Tate JE, Wenk JD, Harris II JM, Parashar UD. Diarrheaassociated hospitalizations among US children over 2 rotavirus seasons after vaccine introduction. Pediatrics 2011; 127:8-15.

11. Ministério da Saúde. Doença diarreica por rotavírus: vigilância epidemiológica e prevenção pela vacina oral de rotavírus humano - VORH (Internet). Portal da Saúde; 2006 Mar. Update 2012 Nov 7. Available at: http://portal.saude.gov.br/

12. Linhares AC. Epidemiologia das infecções por rotavírus no Brasil e os desafios para o seu controle. Cad Saude Publica 2000; 16:629-646.

13. Linhares AC, Garbay YB, Freitas RB, da Rosa EST, Mascarenhas JDP, Loureiro ECB. Longitudinal study of rotavirus infections among children from Belém, Brazil. Epidemiol Infect 1989; 102:129-145.

14. Souza CPR, Araújo DV. Análise do custo de hospitalização por rotavírus e o impacto do tratamento com nitazoxanida. Rev Panam Infectol 2009; 11:33-37.

15. Sartori AMC, Valentim J, de Soárez PC, Novaes HMD. Rotavirus morbidity and mortality in children in Brazil. Rev Panam Salud Publica 2008; 23:92-100.

16. Constenla DO, Linhares AC, Rheingans RD, Antil LR, Waldman EA, Silva LJ. Economic Impact of a Rotavirus Vaccine in Brazil. J Health Popul Nutr 2008; 26:388-396.

17. Secretaria de Estado da Saúde de São Paulo. Informes técnicos institucionais - Vacina contra rotavírus. Rev Saude Publica 2006; 40: 355-358.

18. Salvador PTCO, Almeida TJ, Alves KYA, Dantas CN. A rotavirose e a vacina oral de rotavírus humano no cenário brasileiro: revisão integrativa da literatura. Cien Saude Colet 2011; 16:567-574.

19. Ministério da Saúde. Calendário básico de vacinação da criança (Internet). Brasília (DF): Portal da Saúde. Updated 2012 Nov 7. Available at: http://portal.saude.gov.br/.

20. Palma O, Cruz L, Ramos H, de Baires A, Villatoro N, Pastor D, et al. Effectiveness of rotavirus vaccination against childhood diarrhoea in El Salvador: case-control study (Internet). London (ENG): BMJ; 2010 June 15. Updated 2012 November 7. Available at: http://bmj.com/.

21. Lanzieri TM, Costa I, Shafi FA, Cunha MH, Ortega-Barria E, Li-Nhares AC, et al. Trends in hospitalizations from all-cause gastroenteritis in children younger than 5 years of age in Brazil before and after human rotavirus vaccine introduction, 1998-2007. Pediatr Infect Dis J 2010; 29:673-675.

22. Desai R, Oliveira LH, Parashar UD, Lopman B, Tate JE, Patel MM. Reduction in morbidity and mortality from childhood diarrhoeal disease after species a rotavirus vaccine introduction in Latin America - a review. Mem Inst Oswaldo Cruz 2011; 106:907-911.

23. Carmo GM, Yen C, Cortes J, Siqueira AA, de Oliveira WK, CortezEscalante JJ, et al. Decline in diarrhea mortality and admissions after routine childhood rotavirus immunization in Brazil: a timeseries analysis. PLoS Med 2011; 8:1-11. Epub 2011 Apr 19.

24. Sáfadi MA, Berezin EN, Munford V, Almeida FJ, de Moraes JC, Pinheiro CF, et al. Hospital-based surveillance to evaluate the impact of rotavirus vaccination in São Paulo, Brazil. Pediatr Infect Dis J 2010; 29:1019-1022.

25. Gurgel RQ, Ilozue C, Correia JB, Centenari C, Oliveira SM, Cuevas LE. Impact of rotavirus vaccination on diarrhoea mortality and hospital admissions in Brazil. Trop Med Int Health 2011; 16:1180-1184.

26. Curns AT, Steiner CA, Barrett M, Hunter K, Wilson E, Parashar UD. Reduction in acute gastroenteritis hospitalizations among US children after introduction of rotavirus vaccine: analysis of hospital discharge data from 18 US states. J Infect Dis 2010; 201:1617-1624.

27. Wang FT, Mast TC, Glass RJ, Loughlin J, Seeger JD. Effectiveness of the pentavalent rotavirus vaccine in preventing gastroenteritis in the United States. Pediatrics 2010; 125:208-213.

28. Harris AD, Bradham DD, Baumgarten M, Zuckerman IH, Fink JC, Perencevich EN. The use and interpretation of quasi-experimental studies in infectious diseases. Clin Infect Dis 2004; 38:1586-1591. Epub 2004 May 12.

29. Morillo SG, Timenetski MCST. Norovírus: uma visão geral. Rev Assoc Med Bras 2011; 57:462-467.

30. Parez N, Giaquinto C, Du Roure C, Martinon-Torres F, Spoulou V, Van Damme P, et al. Rotavirus vaccination in Europe: drivers and barriers. Lancet Infect Dis 2014; 14:416-425.

31. Ruiz-Palacios GM, Pérez-Schael I, Velázquez FR, Abate H, Breuer T, Clemens SC, et al. Safety and efficacy of na attenuated vaccine against severe rotavirus gastroenteritis. N Engl J Med 2006; 354:11-22. 